\title{
El debate como herramienta de aprendizaje y consolidación de conocimientos: una propuesta didáctica para el estudio de la comparación y las descripciones de lugares
}

ELIA PUERTAS RIBÉS

Universitat Jaume I

a1373395@uji.es

\begin{abstract}
Resumen: El objetivo principal de este artículo es contribuir modestamente al desarrollo de la enseñanza de español como lengua extranjera. Para ello, la propuesta didáctica que se ha diseñado para este trabajo tiene la finalidad de ofrecer una serie de actividades dinámicas que promueven el desarrollo de las capacidades comunicativas, mediante el léxico relacionado con la ciudad, las descripciones de lugares y la comparación. Además, las actividades están basadas en un enfoque comunicativo, que presenta como tarea final un debate. Ahora bien, pese a que el debate es una herramienta muy trabajada en el aula, cabe destacar la importancia de su integración desde los niveles iniciales (A1-A2) con el objetivo de promover la participación en clase y la expresión e interacción orales. Al mismo tiempo, se fomenta la participación en equipo y se potencia la curiosidad por la cultura, las ciudades y monumentos españoles más interesantes.
\end{abstract}

Palabras clave: español como lengua extranjera, expresión oral, léxico, debate.

The debate as a learning tool and knowledge consolidation: a didactic proposal for the study of comparison and description of place

Abstract: The main objective of this article is to contribute modestly to the development of the teaching of Spanish as a foreign language. For that reason, the didactic proposal that has been designed for this paper has the purpose of offering a series of dynamic activities that promote the development of communication skills, through the lexicon related to the city, the descriptions of places and the comparison. In addition, the activities start from a communicative approach, with a debate as the final task. However, despite the fact that the debate is a highly used tool in the classroom, it is worth highlighting the importance of its integration from the initial levels (A1-A2) with the aim of promoting class participation and oral expression and interaction. At the same time, teamwork is encouraged and curiosity for the most interesting Spanish culture, cities and monuments is enhanced.

Key words: Spanish as a foreign language, oral expression, lexicon, debate.

\section{Introducción}

En el marco de la enseñanza de español como lengua extranjera, ofrecemos una propuesta didáctica para el estudio de la comparación y las descripciones de lugares. Para la elaboración de las actividades, nos hemos basado en el enfoque por tareas, procedimiento pedagógico que establece una serie de ejercicios en torno a un tema y 
cuyo objetivo-meta es la realización de una tarea final, descrita por Estaire y Zanón (2010), como «un paraguas de significación», que representa el punto de mayor potencial comunicativo en la secuencia didáctica y proporciona coherencia al conjunto del trabajo. En este sentido, contemplamos la motivación como un factor fundamental en el aprendizaje, convirtiéndose incluso en el motor que genera el deseo de aprender y el esfuerzo de conocer una lengua nueva (Dörnyei 2009: 29-30). De manera que, es necesario el diseño de las actividades a través de la gamificación, establecida en la docencia de L2 como una de las herramientas más imprescindibles en el proceso de enseñanza-aprendizaje, dado que despierta la curiosidad, facilita la memoria y disipa el aburrimiento o la falta de interés (Dalmases Muntané 2017: 55).

Por su parte, las actividades diseñadas para la unidad didáctica presentan como objetivo principal el aprendizaje de los componentes léxico-gramaticales de nivel inicial (A1A2). De ahí que, hayamos distribuido las tareas en cuatro fases: la primera, la de motivación, consiste en presentar al alumnado el contenido que se trabajará en la unidad. De modo que, a través de la elaboración de una lluvia de ideas, con los conocimientos de los estudiantes, se fomenta la participación en clase y se crea un ambiente de confianza. Seguidamente, en la fase inductiva, se introduce una actividad que consiste en la adquisición de los conocimientos (léxicos y gramaticales) mediante textos, a partir de los que ellos mismos deberán extraer la información más relevante. A continuación, en la de deducción, se utiliza el juego del tabú como la herramienta de producción oral, que consiste en que un estudiante describe una palabra para que el resto de compañeros adivinen cuál es. Finalmente, la de consolidación se establece, primero, de forma individual, con la elaboración de un vídeo y la comparación de estos $\mathrm{y}$, posteriormente, por grupos, se lleva a cabo el debate como tarea final.

Por lo que respecta a la competencia comunicativa, constituida por tres componentes esenciales: el lingüístico, el sociolingüístico y el pragmático, esta unidad trabaja las competencias lingüísticas, concretamente, los conocimientos léxicos y gramaticales. Asimismo, en el Marco común europeo de referencia para las lenguas: aprendizaje, enseñanza, evaluación (Instituto Cervantes 2002) se describen las competencias generales que todo individuo debe poseer para comunicarse en cualquier lengua: el saber (relacionado con la cultura y la conciencia intercultural, entre otras), el saber hacer (habilidades y destrezas), saber ser (referido a las actitudes, valores y creencias) y saber aprender. De ellas, esta propuesta se centra en el saber ser, especialmente, en la competencia cultural de los estudiantes, ya que es importante fomentar el aprendizaje no solo a nivel lingüístico, sino que también hay que promover el interés por la cultura de la lengua que se está adquiriendo (Álvarez Baz 2015: 119). Además, se practica la expresión oral, definida en el Diccionario de términos clave de ELE (Instituto Cervantes 2008) como la «capacidad comunicativa que abarca no solo un dominio de la pronunciación, del léxico y la gramática de la lengua meta, sino también unos conocimientos socioculturales y pragmáticos». Con todo, los materiales elaborados se basan en una concepción comunicativa de la enseñanza de español como lengua extranjera y se centran, principalmente, en el alumnado como eje central en el proceso de aprendizaje.

A partir de aquí, este artículo se estructura de la siguiente manera. En el apartado §2, se presentan los objetivos y la metodología, para seguir en $\S 3$ con la descripción de los contenidos y las competencias desarrolladas. Por su parte, el siguiente apartado (§4) se 
configura como el cuerpo principal de este artículo, en el que se muestra el desarrollo de cada una de las actividades; mientras que en $\$ 5$ se exponen los criterios de evaluación que se siguen a lo largo de la secuencia didáctica. Finalmente, en $§ 6$ procedemos a sintetizar las conclusiones más relevantes extraídas de la implementación de la unidad didáctica.

\section{Objetivos y metodología}

Más concretamente, esta propuesta didáctica tiene como finalidad que los estudiantes sean capaces de describir y comparar cómo son los lugares del entorno más próximo, así como adquirir el vocabulario de las ciudades. Además de:

1. Comprender la información básica proporcionada en los textos.

2. Extraer de ellos los datos más relevantes y averiguar los patrones gramaticales que se utilizan para las descripciones.

3. Explicar los conceptos a partir de los conocimientos gramaticales adquiridos e interactuar con los compañeros para practicar el vocabulario.

4. Elaborar un texto oral con la finalidad de dar información sobre el lugar de origen.

5. Saber comparar las distintas ciudades estudiadas en clase con las de los países de los estudiantes.

6. Reflexionar y aprender cómo son las ciudades españolas.

7. Formular enunciados sencillos con el propósito de defender las ideas del equipo en la tarea final.

Respecto a la metodología, como ya se ha señalado en la introducción, las actividades se han elaborado desde un enfoque comunicativo para convertir a los estudiantes en los agentes del proceso de aprendizaje. Ahora bien, en este transcurso, es imprescindible contextualizar la lengua para que ellos mismos sean capaces de interpretar correctamente los enunciados. Por tanto, en esta unidad, los textos ${ }^{1}$ utilizados se basan en fuentes reales, si bien se ha modificado el vocabulario con el objetivo de simplificarlo y ajustarlo al nivel de los estudiantes. Por otro lado, la propuesta se divide en cinco tareas, la primera se basa en poner en contacto al alumnado con el tema que se abordará, mientras que las cuatro siguientes presentan los conocimientos gramaticales y léxicos que se quieren trabajar. De estas, la tarea final tiene el propósito la cooperación del alumnado tanto para planificar y recoger las ideas del grupo como para discutir e interactuar en clase.

\section{Contenidos y competencias}

Los contenidos que se trabajan son funcionales, gramaticales, léxicos y culturales. Concretamente, se abordan los siguientes:

1. Funcionales:

a. Activación de los conocimientos previos.

b. Identificación y descripción de lugares.

c. Capacidad de formular sencillos enunciados.

\footnotetext{
${ }^{1}$ Todos los textos están extraídos de https:/www.spain.info/ y https://www.red2000.com/spain/.
} 
d. Participación e interacción entre los compañeros.

2. Gramaticales:

a. Comprensión general de textos escritos.

b. Extracción de la información más importante.

c. Comparación de lugares.

d. Utilización de las estructuras gramaticales adquiridas.

3. Léxicos:

a. Descripción de conceptos.

b. Utilización del vocabulario.

4. Culturales:

a. Elaboración y producción de textos orales relacionados con las ciudades.

b. Conversación sobre distintos aspectos de las ciudades españolas y las similitudes y desventajas con las ciudades de procedencia del alumnado.

En cuanto a las competencias, se desarrolla la lingüística, especialmente, la léxica, basada en el vocabulario de las ciudades, y la gramatical, mediante las estructuras sencillas de descripción y comparación. Asimismo, se refuerza la competencia comunicativa tanto con las actividades de expresión oral como las de interacción entre los estudiantes.

\section{Desarrollo de la unidad didáctica}

En este apartado se presentan las cinco actividades diseñadas para implementarse en el nivel inicial (A1-A2) con estudiantes jóvenes y adultos de cualquier procedencia. En nuestro caso, se llevó a cabo, por un lado, con un grupo homogéneo de jóvenes holandeses de edades comprendidas entre los 16 y 18 años; por otro lado, se desarrolló también con un grupo heterogéneo de adultos (entre 23 y 60 años) de distintas nacionalidades. En ambos casos, los alumnos tomaron la decisión de crear sus propios grupos, siempre entre tres y cinco personas, con el fin de que todos participasen. Respecto a la temporalización, para el grupo de adolescentes, las actividades se dividieron en tres sesiones (de 50' cada una). En la primera se desarrollaron las tareas de la lluvia de ideas, textos e imágenes y tabú; mientras que el vídeo por la ciudad de Castellón ocupó la segunda y, finalmente, en la tercera clase, se realizó el debate. Sin embargo, el grupo heterogéneo de adultos necesitó únicamente dos sesiones (de 50' cada una): la primera para las tres primeras actividades y la segunda para la visualización de los vídeos, la comparación de estos y el debate. La reducción de la secuencia en dos sesiones se debe, principalmente a que, en este caso, la elaboración del vídeo se propuso como una tarea para realizar en casa.

\section{Actividad 1: Lluvia de ideas}

La primera actividad sirve para presentar el tema y motivar al estudiante. Para ello, el profesor pregunta qué ciudades españolas conocen, si saben cómo son, dónde están, qué hay, etc. Con ello, se pretende ayudar a los alumnos a que conozcan el contexto que se va a trabajar y, además, que se comuniquen y participen en clase. Para guiar la actividad se puede realizar un esquema visual en la pizarra como el que se ofrece a continuación: 


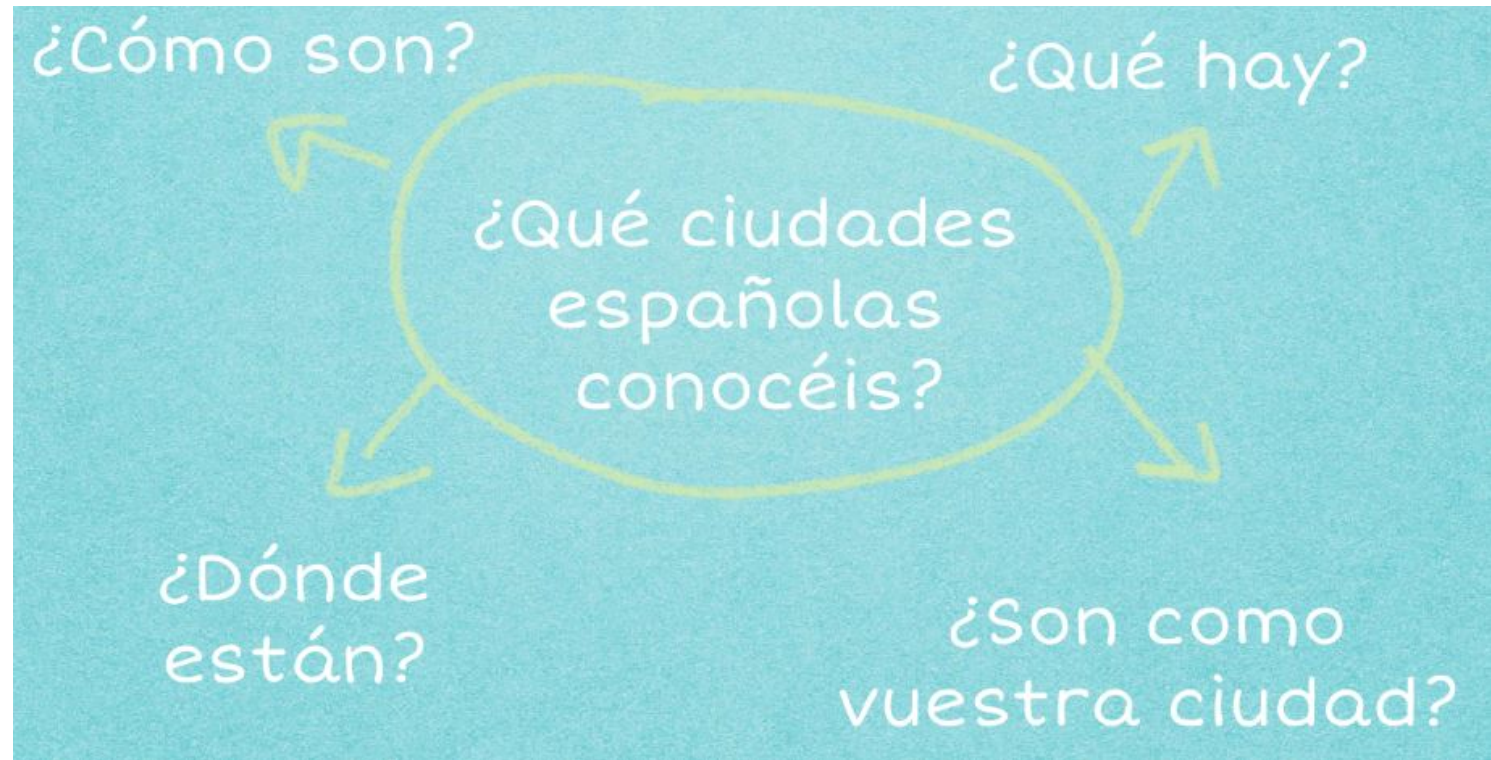

Imagen 1. Lluvia de ideas

En nuestro caso, los estudiantes más jóvenes presentaron mayor dificultad a la hora de activar sus competencias socioculturales. Por tanto, les proporcionamos el nombre de algunas ciudades españolas con el fin de facilitarles el trabajo. En cambio, el grupo de los adultos proporcionó una larga lista de ciudades y pueblos españoles. Finalmente, una vez se ha recopilado toda la información que los estudiantes conocen sobre las ciudades españolas, se les explica que, seguidamente, por grupos, van a realizar la tarea 2 .

\section{Actividad 2: Textos e imágenes}

En esta actividad cada grupo leerá ocho textos, en cada uno de ellos se describe una ciudad española. Así, deberán identificar la información principal para intentar averiguar a qué imagen ${ }^{2}$ corresponde. El objetivo principal de esta tarea es que los estudiantes sean capaces de comunicarse entre ellos y cooperar con el propósito de reconocer los monumentos y edificios específicos que hacen referencia a una determinada ciudad. Por ejemplo, en el siguiente texto (Imagen 2) podemos advertir lugares como el Palacio Real, el Museo del Prado o el Centro Nacional de Arte Reina Sofía, gracias a los que se infiere que estamos ante la capital de España. Con ello, se aprende también vocabulario básico para todas las ciudades (restaurantes, zona comercial, museos, etc.), que les servirá para las actividades siguientes. Seguidamente, tras relacionar los textos con las imágenes y llevar a cabo una puesta en común, se les proporciona una tabla con el nombre de las ocho ciudades y los cuatro verbos conjugados que más se utilizan en las descripciones de lugar (es, está, tiene, hay). Finalmente, se les pregunta si conocen estos verbos y cómo se utilizan en los textos que han leído. A partir de ahí, a través del ejemplo se lleva a cabo la explicación teórica que les permitirá posteriormente elaborar su producción oral.

\footnotetext{
${ }^{2}$ Todas las imágenes están extraídas de https://pixabay.com/es/ y https://unsplash.com/.
} 
Es la ciudad más grande del país y está situada en el centro de la península Ibérica. Tiene una población de más de 3 millones de habitantes. En esta ciudad hay muchos restaurantes con terrazas y cafeterías en la Plaza Mayor, que está cerca del Palacio Real. Junto a él, la Plaza de Oriente, el teatro de la Ópera y la Catedral de la Almudena que es muy moderna. En la Puerta del Sol está la zona comercial, donde hay muchas tiendas. También tiene muchos museos, pero los más importantes son el Museo del Prado, el Museo Thyssen-Bornemisza y el Centro Nacional de Arte Reina Sofía, dedicado al arte español contemporáneo. En esta ciudad hay parques y jardines como el Parque del Retiro, donde hay un estanque para pasear en barca.

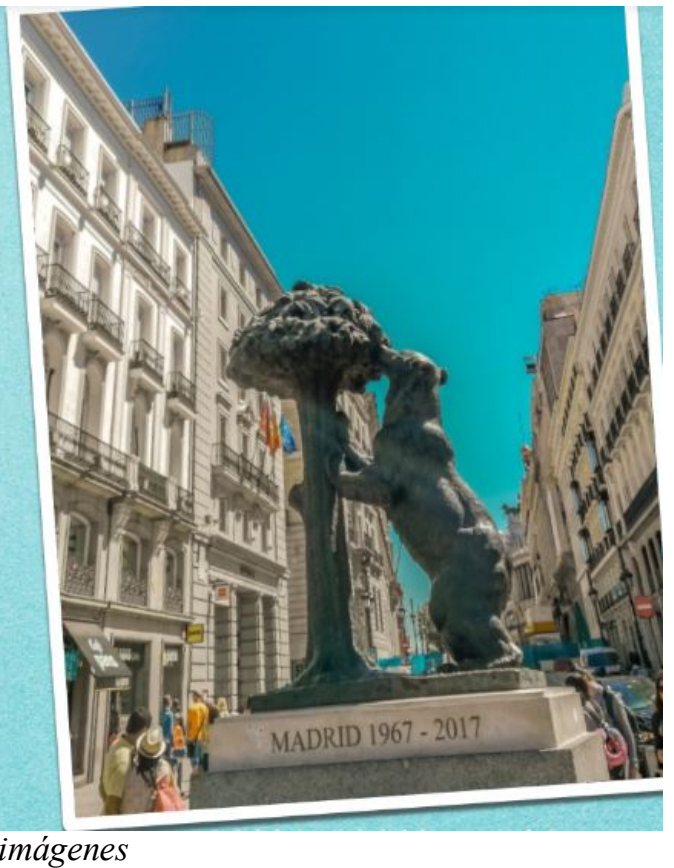

Por su parte, la implementación de esta actividad con el grupo de adolescentes holandeses supuso una buena herramienta para fortalecer los lazos entre los compañeros y, sobre todo, para conocer las ciudades españolas que no conocían. Por el contrario, el grupo de adultos de nacionalidades diferentes presentó mayor facilidad a la hora de reconocer los lugares más emblemáticos y relacionarlos con las fotos. De hecho, los estudiantes que habían visitado algunas de estas ciudades aportaron más información sobre ellas.

No obstante, consideramos que, debido al desconocimiento del vocabulario y los edificios y monumentos que se mencionan, esta es la tarea de mayor dificultad, por lo que se debe guiar a los estudiantes para que puedan llegar a resolver la actividad. De lo contrario, esto supondría una frustración innecesaria en ellos.

\section{Actividad 3: Tabú}

La siguiente tarea pretende fortalecer los conocimientos léxico-gramaticales aprendidos en la actividad anterior. Para ello, se trabaja en un solo grupo y cada alumno recibe varias tarjetas (Imagen 3) con los lugares, objetos y edificios que normalmente encontramos en una ciudad. Seguidamente, intentarán describir las palabras con la ayuda de los verbos estudiados, mientras que el resto de los estudiantes formulará preguntas con el fin de averiguar qué palabra es. De este modo, el juego del tabú nos ayuda tanto a fomentar la expresión oral como a que los alumnos estén concentrados en intentar reconocer los conceptos, al mismo tiempo que se divierten. En este sentido, el juego contribuye a la participación activa y les brinda la oportunidad de cometer errores y aprender de ellos (Jenkins 2009: 37-38), esto es, como afirman Andreu Andrés y García Casas (2000: 124):

La clase se impregna de un ambiente lúdico y permite a cada estudiante desarrollar sus propias estrategias de aprendizaje. Su meta puede ser practicar la lengua, divertirse y/o ganar el juego. Sea cual sea su objetivo, para alcanzarlo utilizará la lengua específica objeto de estudio. 
De esta manera, utilizamos las herramientas que nos brinda la gamificación con el objetivo docente de reforzar la competencia comunicativa, tanto gramatical como léxica. Además, el profesor deja de ser el centro de atención, permitiendo así que los estudiantes se impliquen en la actividad y colaboren con sus propios recursos.

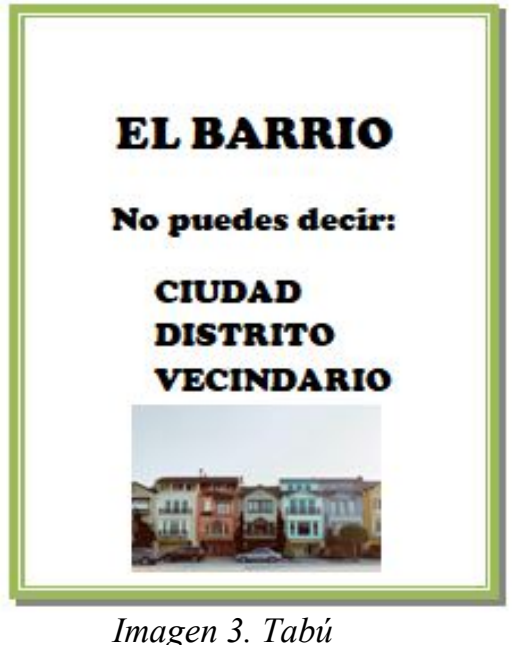

\section{Actividad 4: Vídeo y comparación}

Para el desarrollo de esta actividad, dividida en dos secciones (vídeo y comparación), cada estudiante elabora un texto oral que trata sobre la ciudad natal. Para ello, grabarán un vídeo de aproximadamente dos minutos, en el que emplearán el vocabulario y las estructuras gramaticales. Seguidamente, las grabaciones se proyectarán en clase con la finalidad de que el resto de compañeros formule preguntas sobre las ciudades. Así, se sustituye la tradicional redacción por una producción oral, más dinámica y divertida que les permita expresarse verbalmente.

A continuación, se les explican las estructuras básicas para realizar comparaciones y, a partir de ahí, se vincula esta tarea con la actividad 1 para que los estudiantes comparen y realicen sencillos enunciados, en los que se relacionan las ciudades de origen y las españolas. Tal comparación se puede focalizar, sobre todo, en las localidades españolas en las que residen, ya que son más familiares para ellos.

En nuestro caso, el grupo de holandeses al proceder de la misma ciudad (Ámsterdam) realizó un vídeo sobre la localidad española en la que vivían (Castellón). Para ello, por grupos, salieron a la calle para mostrar en el vídeo los principales monumentos y edificios. En cambio, el grupo de adultos, lo elaboró individualmente y con mucha originalidad, puesto que, mientras explicaban los lugares, adjuntaron fotos para que los compañeros visualizaran mejor las descripciones. A continuación, se abrió un turno de preguntas para resolver dudas e indagar todavía más sobre las ciudades de los compañeros. De esta manera, empleaban sus propias estrategias con el propósito de expresar las curiosidades sobre el vídeo proyectado. Finalmente, el grupo de holandeses propuso realizar un póster, en el que se comparaba su ciudad con Castellón. En cambio, el grupo de los adultos prefirió comentar las similitudes y diferencias oralmente. Respecto a la planificación de esta actividad, la sección dedicada a la comparación se llevó a cabo según lo planificado con el grupo de adultos, con quienes se realizó una producción únicamente oral, mientras que el grupo de adolescentes prefirió trabajar en 
la comparación de ambas ciudades mediante un póster que les sirvió de soporte a la hora de comentar las diferencias.

\section{Actividad 5: Debate final}

La última actividad propuesta para esta unidad didáctica es el debate, establecido en el MCER (MCER 4.4.3.1.) como una de las propuestas más populares para trabajar la interacción oral. De hecho, se trata de una tarea en la que los participantes construyen «conjuntamente una conversación mediante la negociación de significados siguiendo el principio de cooperación» (Martínez Sallés s.f.: 2). En este sentido, se refuerzan también las estrategias cognitivas del discurso con las que aprenden a producir un discurso oral y defender sus ideas, paralelamente, se refuerza la cooperación grupal, tomar y/o ceder el turno de palabra, etc. Se consolidan así los conocimientos adquiridos a través de la expresión e interacción orales.

Para ello, se explica a los alumnos que a continuación participarán un debate, pero primero deben elegir dos de las ciudades españolas estudiadas en clase, por ejemplo, nuestro alumnado optó por Barcelona y Madrid. A continuación, se divide la clase en dos grupos y se plantea la siguiente pregunta: ¿Qué ciudad es mejor para vivir? A partir de ahí, se les ofrece, aproximadamente, 15-20 minutos para buscar información sobre las ciudades, las ventajas, las desventajas, qué se necesita planificar y qué ideas quieren exponer en el debate. Para iniciar el debate, uno de los grupos expone una idea que sirve para comenzar a debatir. A partir de ahí, el equipo contrario responde con los argumentos necesarios para rebatir esa idea y exponer una nueva. Paralelamente, es interesante que durante el debate, todos los alumnos participen por igual, por lo que el docente debe actuar como moderador para asegurarse de que todos reciben al menos un turno de palabra. Asimismo, el profesor debe animar a que con las ideas que se van exponiendo, se comparen y se describan ambas ciudades.

La implementación de esta actividad fue sin duda la que tuvo más éxito. En ambos grupos, los estudiantes realizaron un excelente trabajo de investigación que les ayudó a defender al equipo. Además, para lograr que la discusión se desarrollase correctamente se formularon algunas preguntas clave que les facilitó la búsqueda de información: ¿Qué medios de transporte puedo utilizar? ¿Qué lugares puedo visitar en mi tiempo libre? Durante el debate, fuimos redactando en la pizarra las opiniones e ideas generales que se iban exponiendo para aclarar dudas o cuestiones relacionadas con el léxico nuevo. Por otra parte, consideramos que todos participaron activamente y supieron interactuar, respetando siempre el turno de palabra del grupo contrario.

\section{Criterios de evaluación}

Todas las actividades incluyen en su procedimiento un criterio de evaluación con el fin de observar si se han adquirido los conocimientos. Para ello, el docente tuvo en cuenta que los estudiantes supieran:

1. Comprender la idea general de los textos escritos (actividad 2).

2. Reconocer las ciudades con la información detallada (actividad 2).

3. Elaborar un pequeño discurso sobre su lugar de nacimiento con el vocabulario y las estructuras previamente vistas en clase (actividad 4). 
4. Utilizar los recursos gramaticales y léxicos en la producción oral (actividades $1-4)$.

5. Participar con progresiva autonomía en las diferentes actividades (actividades $1,3,4)$.

6. Ser capaces de producir y comprender información (actividades 2-4).

7. Interactuar con diálogos sencillos (actividades 1-4).

\section{Conclusiones}

En este artículo se presenta una secuencia didáctica que puede llevarse a cabo en el aula de E/LE para aprender los contenidos lingüísticos básicos en los niveles iniciales (A1A2). Para su elaboración, nos basamos en el enfoque comunicativo y por tareas con el fin de ayudar a nuestros los estudiantes a fortalecer tanto sus estrategias de aprendizaje como la habilidad oral. Las actividades van desde las más pautadas, con el soporte de materiales como los textos e imágenes, hasta las menos dirigidas como la producción de un vídeo y la interacción y expresión en el debate. Por otro lado, respecto a la competencia cultura es interesante destacar que, gracias a los materiales proporcionados, los estudiantes más jóvenes pudieron descubrir algunas de las ciudades españolas. De este modo, las pudimos comparar con las suyas y, así, trabajar indirectamente aspectos socioculturales como las tradiciones populares o la música. En cuanto a la realización de las actividades por grupos, consideramos que resultó muy motivador ver cómo los equipos no solo cooperaron en conjunto, sino que también se repartieron el trabajo entre ellos. Por su parte, el debate les sirvió para utilizar distintas fuentes de información con el fin de conocer cómo eran las ciudades de las que se iba a conversar.

Por último, es importante señalar que la unidad didáctica presentada en este artículo puede adaptarse a las necesidades de nuestros alumnos y a sus diferentes niveles, ya que son unas actividades muy flexibles, que permiten la modificación en cuanto al tiempo y los intereses de los estudiantes. De hecho, en nuestro caso, mientras que en el grupo de los adultos no hubo que modificar ninguna tarea, con los holandeses consideramos más apropiado realizar la segunda actividad (textos e imágenes) con el nombre de las ciudades, así como la comparación con sus localidades a través de un póster. Con todo, podemos concluir que las actividades diseñadas son significativamente útiles para favorecer la comprensión de distintos contenidos léxico-gramaticales y la expresión oral. En este sentido, pueden ser muy motivadoras especialmente para estudiantes jóvenes que se sienten más cohibidos a la hora de hablar en una lengua extranjera. Además, las actividades están estructuradas de tal forma que permiten inferir, asimilar y contrastar los diferentes conocimientos antes de producirlos.

\section{Bibliografía}

Álvarez BAZ, A. (2015). «El análisis contrastivo cultural como método de partida en el aula con estudiantes sinohablantes». En Y. Morimoto, M. V. Pavón Lucero y R. Santamaría Martínez (eds.), La enseñanza de ELE centrada en el alumno (pp. 117-130). Madrid: Asociación para la Enseñanza del Español como Lengua Extranjera. Recuperado el 19/02/20, de:

https://cvc.cervantes.es/ensenanza/biblioteca_ele/asele/pdf/25/25_0117.pdf.

Andreu Andrés, M. Á. y GARcíA CASAS, M. (2000). «Actividades lúdicas en la enseñanza de LFE: el juego didáctico», Actas I Congreso Internacional de español para 
fines específicos (pp. 121-125). Madrid: Instituto Cervantes. Recuperado el 20/02/20, de:

https://cvc.cervantes.es/ensenanza/biblioteca_ele/ciefe/pdf/01/cvc_ciefe_01_0016.pdf.

Dalmases Muntané, A. (2017). Uso de la gamificación en la enseñanza de ELE. Alcalá de Henares: Universidad de Alcalá. Recuperado el 02/02/20, de: https://ebuah.uah.es/dspace/bitstream/handle/10017/34583/uso_dalmases_eleando_2017 _N4.pdf? sequence $=1 \&$ isAllowed $=y$.

DöRNYEI, Z. (2009). «The L2 Motivational Self System». En Z. Dörnyei y E. Ushioda (eds.), Motivation, Language, Identity and the L2 Self (pp. 9-42). UK: Multilingual Matters.

EstAire, S. y ZANÓN, J. (2010). «El diseño de unidades didácticas mediante tareas en clase de español», MarcoELE: Revista de Didáctica Español Lengua Extranjera, 11. Recuperado el 26/02/20, de: https://marcoele.com/descargas/navas/21.zanon-estaire.pdf.

INSTITUTO CERVANTES (2002). Marco común europeo para las lenguas: aprendizaje, enseñanza, evaluación. Madrid: Anaya. [Traducción al español de Common European Framework of Reference for Languages: Learning, Teaching, Assessment. Strasbourg: Council of Europe, 2001]. Recuperado el 02/02/20, de: https://cvc.cervantes.es/ensenanza/biblioteca_ele/marco/cvc_mer.pdf.

InSTITUTO CERVANTES (2008). Diccionario de términos clave de ELE. Madrid: SGEL.

Jenkins, H. (2009). Confronting the Challenges of Participatory Culture. Media Education for the 21 $1^{\text {st }}$ Century. EEUU: The MacArthur Foundation. Recuperado el 25/02/20, de:

https://www.macfound.org/media/article_pdfs/JENKINS_WHITE_PAPER.PDF.

MARTÍNEZ SALlÉS, M. (s.f.). «La interacción oral en la clase de ELE: algunas pistas para practicar el español oral de forma sistemática, progresiva y evaluable. Inventario de ideas», Encuentro práctico. Recuperado el 15/02/20, de: https://www.encuentropractico.com/pdf08/interaccion_oral.pdf. 